\title{
Passionate Utterance and Moral Education
}

\author{
Ian Munday
}

\section{Introduction}

In his chapter "Performative and Passionate Utterance" which appears in Philosophy The Day After Tomorrow, Stanley Cavell makes a claim for what he describes as the expressive or passional aspects of speech. This claim (plea might be a more appropriate term) is, in part, a response to what Cavell regards as a missed opportunity or failing in Austin's theory of the performative utterance, an opportunity which philosophers seem unwilling to take up.

In defining the contours of a discussion on passionate utterance, Cavell follows Austin along the path from the discovery/description of the performative utterance and the binary distinction between performatives and constatives, through to the "crisis" (which, for Cavell is in not straightforwardly a crisis) in which that distinction breaks down, and on to the ternary distinction that takes in locutionary, illocutionary and perlocutionary utterances. It is the treatment of the ternary distinction that, for Cavell, brings about a catastrophe in Austin's theorising when the latter, having blown apart the emotivist theory of language, lapses back into the philosophical universe which the discovery of the performative utterance had, so magnificently, departed from.

Cavell's passionate critique of Austin most specifically relates to the latter's neglect of the perlocutionary utterance/perlocutionary effect of the utterance which takes in what is done "by" words. By developing and focusing on perlocutions (which include passionate utterances), Cavell builds on his previous work on the philosophy of language, which has taken into consideration the distinctions between assent and consensus, and has championed the role of the individual voice over submission to conformism.

In attempting to define the felicity conditions for the perlocutionary utterance, Cavell alludes to the requirements of what he calls a moral education. Although Cavell's approach to "moral education" is framed in accordance with a generalizing spirit (Cavell does not refer to the policy or practice of teaching moral education in schools) his discussion of the passionate utterance provides the necessary tools to partake in the debate surrounding educational policy and practice. It should be made clear from the start that a discussion of passion will not partake in a whimsical disavowal of contemporary educational values.

One part of this paper will focus specifically on Michael Hand's discussion of "controversial" issues in "Should we teach homosexuality as a controversial issue?" In the spirit of Austin's proclamation that "there are more ways of outraging speech than contradiction merely", this paper does not aim to "refute" Hand's argument: Hand attempts to find rational arguments for teaching homosexuality as a controversial issue and discovers (in my view, quite legitimately) that there aren't any. Rather, the critique of Hand (and many of the positions which his paper criticises or adheres to) generates from a certain discomfort I felt when considering the relevance of a discussion surrounding the controversiality/non-controversiality of homosexuality. This discomfort derived from my experience, as a practitioner, of witnessing innumerable examples of homophobic abuse in the classroom and playground. Cavell's 
chapter has given voice to that discomfort, for surely, homosexuality is, if anything, at least as much a passionate as a controversial/non-controversial issue.

\section{Crisis}

The crisis, which for Cavell, marks Austin's How to Do Things with Words, derives from the latter's "failure" to make a clear distinction between the constative and performative utterances. ${ }^{i}$ The reason Cavell describes this as a crisis, derives (in part) from the critical reception to Austin's findings, which treats this "failure" as a "flaw" or "aporia" in Austin's project. Cavell, maintains that he does not so much "wish to deny these descriptions as to insist that this critical juncture also represents a signal victory for Austin, for what it shows is that performatives bear the same ineluctable connection with, assessment by, fact, with and by what is the case that statements do (Cavell, 2005, p.168). With his acknowledgement of the different kinds of infelicity, which infect the utterance, Austin will eventually claim that:

...truth (truth itself, so to speak) is to be understood precisely as a dimension of what he calls the criticism of speech. His aim in his study of performatives is at once to lift the non-descriptive or non-assertional or non-constative side of speech to renewed philosophical interest and respectability, and to bring, or prepare the ground on which to bring, the philosophical concern with truth down to size. (Ibid, p. 159)

Having enacted this "revolution" on philosophy, Austin moves from the binary distinction between constatives and performatives, on to a ternary distinction. Here, the performative utterance is considered in terms of the locutionary aspect (the form of the words), the illocutionary force (what is done with words) and the perlocutionary effect (what is done by words). It should be noted that Austin also describes specific utterances as illocutions and perlocutions. It is Austin's elaboration of this ternary distinction, in which the perlocutionary effect is left out in the cold, which brings about what Cavell (cautiously) describes as the catastrophe in Austin's theorizing.

\section{Catastrophe}

Whereas Austin argues that every performative utterance must necessarily be a locution and possess illocutionary force, he is hesitant when it comes to dealing with the perlocutionary effect of the utterance. For Cavell this hesitancy takes on catastrophic dimensions when Austin claims that: "Clearly any, or almost any, perlocutionary act is liable to be brought off, in sufficiently special circumstances, by the issuing, with or without calculation, of any utterance whatsoever, and in particular by a straightforward constative utterance (if there is such an animal)" (Austin, 1976, p.110). Cavell argues that here, Austin appears to be reiterating Stevenson's infamous claim that "Any statement about any matter of fact which any speaker considers likely to alter attitudes may be adduced as a reason for or against an ethical judgement" (Cavell, 2005, p. 174) Cavell argues that for many reasons, Austin's closeness to Stevenson in this matter is extremely bizarre. To begin with, Austin's typical rigour when analysing and counting is strangely lacking from his approach to perlocutions. Also, considering the importance of felicity conditions in establishing the happiness of a performative utterance, it would seem extremely peculiar to conclude that there are no happy or unhappy effects of an utterance. By the same token, can an individual really be held 
responsible for "any" effect, which their utterance brings off? Here is Cavell considering the possible effects of saying "it would be scrumptious to hear you sing":

There is no end to the things that happen to people. If you begin to cry upon hearing my words, I might think I had bumped against a sore point, that perhaps I had not heard that something had happened to your voice. But for someone to say that I did it, that the tears were (the effect of) what I did by saying what I did, seems not merely unfair in this case (as Austin describes accusations that would set aside excuses in physical [literal?] cases of doing something untoward); paranoia has shown its hand. (ibid, p. 179)

Although, any effect may follow on from my utterance, it is important to note, that I will not necessarily be responsible for that effect. For Cavell, the marginal importance/external nature, which Austin allocates to the perlocutionary effect, clashes with the importance of responsibility, which marks the latter's treatment of moral issues. This is particularly noticeable when we again consider Austin's account of promising in which "the use of metaphysical or other false profundities to avoid one's ordinary commitments (here the commitment to listen to one whom you have questioned) is noted early in How To Do Things With Words as the ulterior philosophical vice or temptation that the theory of performative utterances is most explicitly interested to combat (ibid, p.176). Nevertheless, Cavell is not content to let a much loved teacher simply stew in his own contradictions, but attempts to find explanations for Austin's at best tentative, at worst contradictory treatment of perlocutions. Some of these explanations are stated in quite an explicit form, others are not. The more subtle explanations derive from Cavell's recognition of the dominance of Ayer and Stevenson's work on the philosophy of the time. The fact that Cavell should go to such lengths to impress upon the reader how influential these figures were, provides an historical backdrop that might help us understand the hesitancy, which often marks Austin's philosophy, particularly when he is at his most inventive. Nevertheless, there are more explicit reasons, which throw some light on Austin's approach.

One of the reasons, which Cavell cites for Austin's relative disinterest in perlocutions derives from the latter's adherence to convention. When we make a performative utterance, there is no denying that we have "done" something. We can then adhere to a set of conventions (felicity conditions) to decide whether or not the utterance is happy. In the case of perlocutions, the matter is much more complicated. Cavell takes pains to point out that, whereas we can say "I christen you" or "I marry you", and will have done something, we cannot say "I frighten you" or "I interest you" and necessarily have said anything at all; these sentences don't appear in English in this form (ibid, p. 171).

Cavell focuses on the fact (which Austin also mentions) that "performative" or "illocutionary" utterances take the form of the first person singular present indicative active. Perlocutions don't fit in with this schema, because for the sentence "I frighten you" to be happy, I would have to be exercising some kind of magical power over you. Consequently, Cavell indicates that Austin's suspicions regarding perlocutions partly stem from the latter's distaste for political rhetoric, which partakes in the insincerity, which his philosophy rails against. However, the fact that by saying "I frighten you" does not mean that I have succeeded in frightening you, should not be the end of the matter, but opens up a new field of enquiry. This is because, whether or not my words, and the way I express those words, succeed in frightening you depends, to a large extent on "you" as much as it does on me. Consequently, taking serious notice of the perlocutionary effect is to acknowledge the individual/expressive 
uses of speech in which people establish relationships with one another. Not everyone is capable of frightening, or seducing, or alarming other people. The skill or talent to perform these acts is not "equally distributed amongst the species" (ibid, p. 173).

Cavell is interested in perlocutionary acts precisely because they are unconventional. He shows that perlocutionary acts make room for imagination and virtuosity, that consequently, there is no "one size fits all" (ibid) criterion for perlocutions: "Passionate expression makes demands on the singular body in a way illocutionary force (if all goes well) forgoes" (ibid).

\section{What is a passionate Utterance?}

Cavell is cagey when it comes to defining the "passionate utterance". His discussion of the "passionate utterance" defines it in terms, which fluctuate between negation and affirmation. For example, we are told that passionate utterances do not exhaust the field of the perlocutionary (ibid, p. 177) so that we may simply adduce that passionate utterances are "one" form of perlocution. Cavell is also keen to point out that passionate utterances are "ordinary exchanges" and that, for example, if a judge utters the words "you were wrong", this has illocutionary force, as it can amount to a sentence. The words "ordinary" and "exchanges" are clearly heavily loaded here. That Cavell wishes to occlude the judge's verdict from the field of the ordinary is very telling; he clearly maintains that the language of the courtroom should not be thought of as "ordinary", the reason being (this is not the only reason!) that it is not an "exchange" as such. A study of the passionate utterance (and perlocutions generally) involves the recognition of the individual, both as self and other, which becomes distorted (perhaps sidelined) in the case of illocutionary force. I say distorted rather than negated in compliance with Cavell's point that illocutions do not silence the other. Rather they signal the end of the matter; the convicted criminal may protest the verdict, but this is hardly an exchange, as we may "ordinarily" understand that term. Passionate utterances, as such, require "exchange not mediation or arbitration" (ibid). Cavell provides examples of passionate utterances. Here are four of his examples:

(a) "I'm bored"

(b) "You know he took what you said as a promise" (Roughly a rebuke from Margaret Schlegel to Mr. Wilcox in Howard's End. I cite this to invoke and further contextualize the examples of moral encounter in my Claim of Reason (pp.265267)

(g) "They say I (or perhaps I; or: I would not wish to) anger, mortify, charm, affront, encourage, disappoint, embarrass, confuse, alarm, offend, deter, hinder, seduce, intimidate, humiliate, harass, incite, etc. you."

(h) "You (or: Are you attempting to...?) anger, mortify, charm, affront, disappoint, embarrass, confuse, etc.” (ibid, pp. 177-178)

Cavell says of these examples that (1) they are obviously meaningful (clearly a response to Ayer) (2) they're not meant to inform their addressees although most of them are true or false (ibid, p.177 - 178). Cavell chooses "I'm bored" because it is one of Ayer's examples which the latter uses to argue for "the primacy of expression over emotion" (ibid, p. 178). Ayer claims that such expressions do not necessarily involve assertions at all. Cavell, doesn't deny 
this, but makes the point that: "If not to "involve assertions" or words in your expression means to keep silent, this may come from being silenced, from not wanting to say something" (ibid, p. 179). Here, Cavell is making philosophy work with the situations in which words are uttered (a very Austinian move, and quite deliberately so). Expressions, which are not necessarily verbalised, are (sometimes) not verbalised due to the force of convention, that this conventional (illocutionary?) force can stultify speech. For Cavell, such a reigning in of speech is clearly a moral issue.

In Cavell's second example of passionate utterance - "You know he took what you said as a promise", he is clearly returning to old territory. In The Claim of Reason, shortly before displaying this example, Cavell writes:

The moral significance of how an action is described, the problem in saying what it is which is under scrutiny, suggests that the epistemological "foundation" so often sought for morality, the "knowledge" which is to "base" our moral conduct and judgement, is a knowledge of persons, an epistemology which explains and assesses our claims to know what anyone is doing, and the basis on which one describes one's own action. (Cavell, 1979, p. 265)

Now, we might say, that here, Cavell is performing the very Austinian task of bringing philosophy's obsession with truth down to size. Epistemological concerns (narrowly conceived) qualify as only one aspect of a moral judgement. Cavell demonstrates what he means by looking at "strictly" epistemological contexts. The example he uses refers to the question of whether or not it is a goldfinch that has fallen from the tree. He mentions how, for example, simply noting that the bird has a red head means that the argument that it is a goldfinch is insufficiently supported. If, during this encounter, I say: "But that's not enough" there is no room for you to say: "For me it is enough". However, in moral cases "What is enough" is "itself part of the content of the argument". Consequently, "what is enough" "must be determined by me". Also, what I cannot do, if I wish to "maintain my position as morally competent, is to deny the relevance of your doubts". (ibid, p. 267)

Basically, Cavell is extending the scope of epistemology to include the specifics of the individual/other (as an individual) rather than treating these figures as external concerns. We might say, that the account of passionate utterance helps to justify and reinforce this idea. This is backed up when we return to the examples (g) and (h) which require "disclaiming functions" due to the difficulties mentioned earlier regarding the fist person pronoun, which again demonstrates the importance of exchange over convention when it comes to perlocutionary verbs. This is elaborated on when Cavell is at his most explicit in his application of Austinian methods to deal with the "missed opportunity" which marks How To Do Things with Words. I am referring here, to the moment in which Cavell constructs his own set of felicity conditions for perlocutions (Cavell, 2005, p. 180-182). When presenting his new set of conditions, Cavell also includes Austin's conditions relating to success of the "performative" utterance, so as to demonstrate how they deconstruct under the duress of the expressive/passionate/perlocutionary utterance. This involves showing how an adherence to convention, is challenged by highlighting the avoidance of conformity necessary for a happy perlocution:

Austin's Illocutionary Condition 1: There must exist an accepted conventional procedure having a certain conventional effect...to include the uttering of certain words by certain persons in certain circumstances. 
Analogous Perlocutionary Condition 1: There is no accepted conventional procedure and effect. The speaker is on his or her own to create the desired effect. (ibid, p. 180)

On first inspection, this looks like a simple overturning/negation of convention in favour of the expressive aspects of speech; the perlocutionary conditions appear to be defying convention, rather than submitting to it. Mulhall succinctly explains the dangers of treating the passionate utterance as simply the negation of the performative utterance. He argues that when Cavell recognises that "my idea of passionate utterance turns out to be a concern with performance after all", he:

...wishes his idea of passion internally to modify Austin' idea of the performative, to subject it to internal transformation. His goal is not to counterbalance the idea of order with that of disorder, but to suggest that Austin's idea of the dimension of law in which speech necessarily participates must be one that makes room for - makes possible - the ways in which speech allows us to improvise our way through the disorders of desire. (Mulhall, 2006, p.5)

Cavell is not trying to show that we can escape the conventions of speech (the law) - the deconstructive dimension of his new set of felicity conditions requires the old conditions, which may be destabilized, but are not negated.

Cavell notes that for Illocutionary Conditions $2 \mathrm{a}$ and $\mathrm{b}$ ( 3 and 4 in Cavell's numbering system) there are no analogous perlocutionary acts. With his last condition for perlocutions, Cavell registers "a final asymmetry" with Austin's conditions, and adds one of his own:

Perloc 7: You may contest my invitation to exchange, at any or all of the points marked by the list of conditions for the successful perlocutionary act, for example, deny that I have that standing with you, or question my consciousness of my passion, or dismiss the demand for the kind of response I seek, or ask to postpone it, or worse. I may or may not have further means of response. (We may understand such exchanges as instances of, or attempts at, moral education. (Cavell, 2005, p.183)

Here, Cavell is obviously, in one sense, "extending" Austin's contribution by refiguring the total speech act situation so that it is resistant to closure (in the case of passionate utterance at any rate). As with Cavell's aforementioned approach to moral issues in The Claim of Reason, the possibility for "exchange" is part of the content of the utterance. Issues pertaining to truth or epistemological "reasons" make up only one facet of the situation. Otherwise, we negate the possibility for "improvisation in the disorders of desire". Moral education, as such, necessarily involves the constant possibility of exchange and cannot be impoverished by an "absolute" (following Mulhall) appeal to convention, which one might assume, would result in the "moralism" that accompanies "instruction".

\section{A Passionate Response To Hand}

Although the term "moral education" is used in its most general sense by Cavell, this does not detract from the possibilities his arguments present to a debate on educational policy and practice. To demonstrate how this might work, I will attempt to bring Cavell's analysis to bear on the issues raised in Michael Hand's paper "Should we teach homosexuality as a 
controversial issue. In employing, what I take to be, Cavellian tactics, the aim is not to contradict Hand, or attempt to refute his argument, but rather to consider the implications, which derive from his particular approach. Invoking Cavell's treatment of the passionate utterance, I will attempt to show that in a complicated (unconventional?) way, Hand's paper partakes in a form of moralism (Hand's paper is not moralistic in a conventional sense), which Cavell is trying to counter.

My particular reasons for approaching Hand's paper derive, in part, from a sense of personal frustration; I attended the paper (in the Gregynog conference) and failed to successfully articulate my conflicting feelings about Hand's argument. Cavell's discussion of passionate utterance has provided the tools to attempt a response.

Hand begins his paper with some strong assertions:

When we tackle moral questions in the classroom, we have two options open to us. One is to provide pupils with substantive moral guidance, to teach moral questions with a view to promoting particular answers to those questions. The other is to ach moral questions as controversial issues, to make a deliberate attempt not to steer pupils towards particular answers but rather to be as even-handed as possible in the presentation of conflicting views. For convenience I shall refer to these options as the directive and non-directive approaches to teaching moral questions. (Hand, 2006, p.1)

Now, without trying to be pedantic, it might be useful to consider Hand's use of the metaphor "to tackle"; it suggests a form of activity, which gains control of something, which is already there. The sight of this "something" (moral issues) is the classroom. However, the two options (only two?) open to us, seem to have little to do with anything that "happens" in the classroom, most specifically, "tackling". Rather, they relate to a decision making process that precedes entry into the classroom and help to define what "we" as teachers, or "I" as a teacher, decide to do. In a climate, currently obsessed with student-centred pedagogies, Hand's binary distinction governing the possibilities for teaching moral education, may seem slightly anachronistic to modern practitioners. Looked at from this (student-centred) perspective, both the directive and non-directive approaches belong to the same camp because the emphasis is on what the "teacher" "does" - either steering or not-steering. The obvious problems, which surround Hand's distinction, pertain to the role in moral education played by the students (in a Cavellian sense, the role of the "you"). We shall return to this shortly.

During the discussion following Hand's paper, I suggested that homosexuality was not simply a controversial issue in modern schooling but was "the" controversial issue. I attempted to back this up by pointing out that that the issue of homosexuality constantly raised it's head in the form of homophobic abuse, that consequently teaching on homosexuality was an everyday occurrence which was not confined to PSHE lessons. Hand responded by saying that his paper was not really concerned with this issue; he was trying to establish whether or not there were sound arguments for teaching homosexuality as a controversial issue.

Spending time with Cavell's chapter on passionate utterance has caused some reassessment of my comments to Hand and what I meant when I said that homosexuality was "the" controversial moral issue in schools. It now occurs to me, that I was trying to describe was a condition in which issues pertaining to homosexuality were, for many students, the most passionate. Now, whether or not Cavell would be willing to accept some of the comments 
made by my students in this respect as passionate utterances is clearly contentious. This is because Cavell draws a distinction between hate speech and passionate utterance, maintaining that they are different forms of perlocution. ${ }^{i i}$ However, there is no denying the expressive aspects of "hate speech". Also, I can think of many occasions in which students have passionately expressed their irritation with homophobic language.

Anyway, returning to "Should we teach homosexuality as a controversial issue?" Hand initially structures his argument by looking at the different theories, which deal with the criterion for establishing controversiality. Ultimately, he discards most of these approaches and settles on Dearden's “epistemic criterion". Here is Dearden:

...a matter is controversial if contrary views can be held on it without those views being contrary to reason. By 'reason' here is not meant something timeless and unhistorical but the body of public knowledge, criteria of truth, critical standards and verification procedures which at any given time has been so far developed. (Dearden, in Hand, 2006, p.3.)

It should be noted that, in adopting Dearden's approach, Hand is not attempting to base the rightness of his arguments on metaphysical foundations. Instead, he attempts to discover rational arguments for treating homosexuality as a controversial issue and (quite legitimately) fails to find any. He consequently concludes that homosexuality should not be taught as a controversial issue.

As I said before, it is not that I disagree with Hand's findings (as they are developed within his chosen perameters), but it is rather his "epistemological" approach, which engenders some consternation. This concern develops, in part, from Cavell's recognition that epistemological factors (when epistemology is limited to giving reasons) should not be the governing concern when considering moral issues. Consequently, by taking the approach that homosexuality is not a controversial issue, Hand's argument seems to imply that teachers should stifle those "ordinary exchanges" which can become "instances of, or attempts at, moral education". It implies that, as a teacher, I must "deny that I claim any particular standing with you in order to confront you, and my utterance may therefore claim authority to speak for a particular institution, with its own ordinances, or for morality as such, and risk moralism" (Cavell, 2005, p. 182). This is because Hand's argument exercises illocutionary force over certain utterances that pertain to a specific moral issue; those utterances are silenced before they can even enter the realm of the debate. This necessarily entails that the kind of responsibility to the individual as an individual and the other (as an individual other) is not permitted to enter the picture.

With his focus on epistemological concerns, Hand's argument gives tacit agreement to a form of moral philosophy that has no place for the expressive in speech. Clearly Hand is no emotivist; he is not reiterating the fact/value distinction. However, his failure to recognise that "what counts as enough" is part of the content of a moral encounter serves to narrow his line of argument. It should be noted here, that I am not suggesting that teachers should simply present the arguments for and against thinking of homosexuality as a controversial issue. I might even suggest that they introduce Hand's excellent arguments to confront homophobic utterances. I find that I share the same moral universe as Hand, why should I deny that opportunity to my students. Here is Cavell: 
But if what I have been aiming at is indeed some fragment of a view of expression, of recognizing language as everywhere revealing desire - ... this is meant in service of something I want from moral theory, namely a systematic recognition of speech as confrontation, as demanding as owed, ...each instance of which directs and risks, if not costs blood. (Cavell 187)

Although teachers generally wish to avoid bloodshed, the kind of moral encounters (often initiated by the students themselves), which relate to the issue of homosexuality, need "tackling" because a response is "owed". Cavell is aware that by focusing on "passion" he may be accused of "calling for an anti-morality", but maintains that he "would rather think of it as "a refusal of moralism". Cavell clearly fears (covets?) such accusations because he might be taken to occlude convention from moral encounters. However, as the earlier reference to Mulhall indicates, the "law" can be broken but it does not disappear from view.

This discussion can be illuminated by a consideration of the distinction Cavell draws between the impersonal metaphysical voice of modern philosophy (Hand would only represent the impersonal aspect of this voice) and ordinary language philosophy. Here is Standish:

In contrast to the impersonal metaphysical voice of modern philosophy, which states or questions what is the case, ordinary language philosophy characteristically proceeds with expressions, as we saw, of the form 'When we say...we mean...'. The verbal form here is first person, which authorises the judgement, and plural, which binds the speaker to the community. And this statement is made not as some kind of empirical generalisation; a survey of usage, for example, would be beside the point. It is made rather as something closer to a commitment or an expression of assent, depending both upon the sincerity of the speaker (how it seems to her) and on her affirming her alignment or community with others (her faith that she shares this judgement with them, can speak for them). In this, then, Cavell mitigates any tendency towards the 'subliming' of rules by throwing emphasis on the location of rule-following practices in the hurly-burly of the form of life, the cohesion of which depends on agreement in judgements. (Standish, p. 94)

As with his insistence on perlocutions, "voice" is important in Cavell's approach to "assent". Here, we might note a distinction between the forced consensus, which would derive from avoiding encounters which bring into question the legitimacy of moral judgements, and the "assent" which can be derived from negotiations which take place in "the hurly burly of the form of life'. If, in the teaching of moral education we are to do justice to our students, then this "commitment to an expression of assent" will not lead to chaos. Rather, it will promote shared entry into a common world.

\section{Conclusion}

Let me summarise the argument in schematic terms:

1. Cavell recognises a catastrophe in Austin's treatment of his ternary distinction in which, due to their "unconventional nature", perlocutions fail to fit in neatly with his conception of a performative/illocutionary utterance. 
2. Consequently, Cavell unveils the possibilities presented by perlocutions (which include passionate utterances), recognising that their power lies in their unconventional nature; they celebrate individuality and call for the assent of the other.

3. During his development of/break with Austin's project, Cavell develops a set of felicity conditions, which apply to perlocutions.

4. Cavell's final condition for perlocutions uncovers an approach to moral education, which demands to be heard just as much as it demands that others be heard. This will avoid a form of moralism, which fails to account for the expressive aspects of the utterance.

5. I bring Cavell's findings to bear on Hand's paper "Should we teach homosexuality as a controversial issue" and argue that homosexuality is just as much a passionate as a controversial issue.

6. This involves a critique of the narrow epistemic criterion, which Hand mobilises during his argument. I go on to suggest that Hand's argument applies an illocutionary force to the treatment of issues surrounding homosexuality, which stifles the expressive dimension of speech and silences the other.

7. By acknowledging the passional/expressive side of speech, I suggest that teachers can help facilitate entry into the "shared realm of reason" (Cavell, 2005, p.188)

Although this is a matter for another paper, Cavell's approach to the passionate utterance makes room for a powerful critique of the treatment of the individual in contemporary schooling. It should be noted that moral education, as yet, has not been dragged into the assessment industry. In an educational climate, which covets individuality as it converts it into statistical information (through various performative mechanisms), an acknowledgement of the expressive/passional in speech allows a glimmer of light to seep through.

\section{Notes}

i For those not familiar with Austin's work on the performative, here is a brief outline of key points. The crisis identified by Cavell, can be found in Austin's initial recognition that there are utterances, which are not nonsense and cannot be thought of in terms of truth and falsity. Such utterances include "I christen this ship the..." "I now declare you man and wife" and "I promise". Austin notes that to utter such sentences is:

...not to describe my doing of what I should be said in so uttering to be doing or to state that I am doing it: it is to do it. None of the utterances cited is either true or false: I assert this as obvious and do not argue it. It needs argument no more than "damn" is not true or false: it may be that the utterance "serves to inform you" - but that is quite different... When I say, before the registrar or altar, etc., "I do", I am not reporting on a marriage: I am indulging in it. (Austin, 1976, p.6)

Austin calls such utterances, which "do" things "performatives", and draws a binary distinction between performatives and constatives. Constative utterances state things and can be considered in terms of truth and falsity. Having made this distinction, Austin focuses on the performative utterance and is obliged to consider the "constraints or conditions that they operate under which ensure that they communicate or do their work as perfectly as they do, as perfectly as the most unobjectionable true-or-false statements do theirs (Cavell, 2005, p.158). Austin calls such constraints felicity conditions. He identifies six conditions: 
(A.I) There must exist an accepted conventional procedure having a certain conventional effect, that procedure to include the uttering of certain words by certain persons in certain circumstances, and further,

(A2) The particular persons and circumstances in a given case must be appropriate for the invocation of the particular procedure invoked.

(B.I) The procedure must be executed by all participants both correctly and

(B.2) completely.

(ГI) Where, as often, the procedure is designed for use by persons having certain thoughts or feelings, or for the inauguration of certain consequential conduct on the part of any participant, then a person participating in and so invoking the procedure must in fact have those thoughts or feelings, and the participants must intend so to conduct themselves, and further

(Г2) must actually so conduct themselves subsequently. (Austin, 1976, pp. 14-15)

Following his account of the different kinds of infelicity, Austin makes a hesitant entrance into an area, which marks a dramatic about turn in his thinking on the distinction between the constative and he performative. Here is Austin:

Lastly, we may ask - and here I must let some of my cats on the table - does the notion of infelicity apply to utterances, which are statements? So far we have produced the infelicity as characteristic of the performative utterance, which was 'defined' (if we can call it so much), mainly by contrast with the supposedly familiar 'statement'. (ibid, p. 20)

Austin notes G.E.Moore's recognition that saying 'The cat is on the mat' "implies" that I believe it to be so. It may be that the cat is not on the mat despite my belief that it is. However, I cannot say that 'the cat is on the mat' alongside 'I do not believe that it is'. Ayer's example introduces felicity conditions into the equation, for if I say that the cat is on the mat but do not believe that it is, then I $\mathrm{m}$ being insincere. This causes Austin to point out that: "the unhappiness here is, though affecting a statement, exactly the same as the unhappiness infecting 'I promise...when I do not intend, do not believe, \&c.” (Ibid, p. 51) We can therefore observe that the elements of intentionality, which accompany a promise and make it felicitous or infelicitous, also apply to statements. Indeed, G.E.Moore's observation is already pointing towards the idea that a statement is something delivered by "somebody"!

Austin's point that "we are assimilating the supposed constative utterance to the performative" is interesting. It would appear that he is creating a hierarchy in which the previously unrecognised performative utterance has swallowed up or colonized the constative utterance. In fact, is he not suggesting that truth statements, the staple diet of much philosophy, can no longer be approached as discrete units of knowledge, and must be thought of in terms of utterances, which "do" rather than simply "state" something? If How to do Things with Words had ended at this juncture, then the answer would have to be in the affirmative. However, things are not so straightforward. Austin's example of the warning in response to a charging bull provides pause for thought:

'I warn you that the bull is about to charge' is the fact, if it is one, that the bull is about to charge: if the bull is not, then indeed the utterance 'I warn you that the bull is about to charge' is open to criticism but not in any of the ways we have hitherto characterized as varieties of unhappiness. We should not in any case say that the warning was void - i.e. that he did not warn but only went through a form of warning - nor that it was insincere: we should feel much more inclined to say that the warning was false or (better) mistaken, as with a statement. So that considerations of the happiness and unhappiness type may infect statements (or some statements) and considerations of the type of truth and falsity may infect statements (or some statements) and considerations of the type of truth and falsity may infect performatives (or some performatives). (ibid, p. 55)

Here, Austin is questioning the assimilation of the constative to the performative utterance. He shows that just as considerations of happiness "infect" constative utterances, considerations of truth and falsity "infect" performative utterances. Here, the assimilation process is working in both directions; in certain instances the performative utterance will be assimilated by conditions applicable to the constative. Nevertheless, the bracketed "(or some performatives)" suggests that the colonization of the performative is limited to specific utterances, and is not, therefore, always applicable. The performative is still in the ascendancy. 


\footnotetext{
ii In "Performative and Passionate Utterance", Cavell is keen to save Austin from certain readings of his work (which often feature in gender studies) which assimilate the performative with "hate speech". Cavell makes it clear that examples of "hate speech" are perlocutions, not illocutions.
}

References

Austin, J.L. (1976) How to do things with Words, ed. J.O.Urmson and Marina Sbisa (London, Oxford University Press)

Cavell, S. (1979) The Claim of Reason (New York, Oxford University Press)

Cavell, S. (2005) Philosophy The Day After Tomorrow (Cambridge, Massachusetts, Harvard University Press)

Hand, M. (2006) "Should we teach homosexuality as a controversial issue" (paper presented at the Gregynog Philosophy of Education Conference, July)

Mulhall, S. (2006) "Suffering a Sea Change: Crisis, catastrophe, and convention in the theory of speech acts" in Reading Cavell (London, Routledge)

Standish, Paul. (2004) "In Her Own Voice: Convention, conversion, criteria" in Educational Philosophy and Theory, 36:1, pp.91-106

\section{Ian Munday}

University of Sheffield

589 Middlewood Road,

Sheffield,

S61TN

$\underline{\text { mundayian@yahoo.co.uk }}$ 